\title{
DR-1788
}

[1-4]

\section{Effect of Conditioning Methods on Mechanical Properties of Raw Bael Fruit}

\begin{abstract}
Background: Bael is an important indigenous fruit, which is rich in nutritional and health promoting factors. Development of valueadded products from this fruit poses a problem as the fruit has a hard rind and is difficult to be removed by hand.

Methods: The objective of this investigation was to evaluate the effect of different conditioning methods as normal water dipping (25$\left.27^{\circ} \mathrm{C}\right)$, chilling $\left(10-11^{\circ} \mathrm{C}\right)$, freezing $\left(4-5^{\circ} \mathrm{C}\right)$ and hot water dipping $\left(90-95^{\circ} \mathrm{C}\right)$ on firmness and other mechanical properties of raw and matured bael fruit, with a goal of devising some methods for easy removal of the rind. The fruits after conditioning were subjected to puncture test by universal testing machine. Distinct peaks were observed on the force-displacement traces which indicated the rupture force and firmness of the fruits. The changes observed in rupture force, deformation and firmness in conditioned samples were compared.

Result: Rupture force measured for control sample (kept under ambient conditions) was $344.4 \pm 27.13 \mathrm{~N}$ and was found to be lower than that of the conditioned samples. The minimum rupture force of $192.6 \pm 14.41 \mathrm{~N}$ was observed in frozen sample. No significant difference in rupture force could be observed between the normal water dipped sample and chilled samples. Hot water dipped sample required a rupture force of $215.3 \pm 29.2 \mathrm{~N}$, which was not significantly $(p>0.05)$ less than those of other treatments but, the green color of the fruits degraded to brown. The change in other mechanical properties also remained similar. The results would be useful for preparing the raw bael fruit for further processing and value addition.
\end{abstract}

Key words: Bael fruit, Conditioning method, Firmness, Puncture test, Rupture force, Toughness.

\section{INTRODUCTION}

Bael [Aegle marmelos (L.) Correa] a member of Rutaceae family, is an indigenous subtropical forest fruit crop native to Indian subcontinent and Southeast Asia. In India, the total production of bael is 85.83 thousand tonnes out of which Odisha contributed about $56.57 \%$ as highest among all states (NHB- Annual Statistical Report, 2015-16). The fruit is a well-known for its therapeutic properties due to the presence of the bioactive compounds like marmelosin, polyphenol, carotenoids, alkaloids, coumarins, tannins etc. (Bhardwaj and Nandal, 2015). All the parts of this tree including leaves, roots, stem, bark, seed and fruits having different maturity stages have extensively used as traditional medicine. Hence it has special importance to Unani and Ayurveda. It has a highly significant therapeutic potential and nutritional values and also has great curative effects on various diseases like dysentery, diarrhea, diabetes, cough and various stomach disorders (Singh et al., 2014). Bael contains important medicinal properties which make it antidiabetic, anti-pyretic, anti-microbial, anti-inflammatory, analgesic, cardioprotective, anti-spermatogenic, anti-cancer, radioprotective, antioxidant, antibacterial, antiviral, antidiarrheal, gastroprotective and anti-ulcerativecolitis effect (Baliga et al., 2011, Lakht-e-Zehra et al., 2015).

The medicinal properties of raw or half ripe bael fruit is high when the harvesting of fruits is just beginning to mature. The antioxidant property of raw bael is higher compare to ripe bael due to the presence of vitamin C, tartaric acid, malic acid, tannins, or mucilage components. The medicinal
Department of Agricultural Processing and Food Engineering, College of Agricultural Engineering and Technology, Odisha University of Agriculture and Technology, Bhubaneswar-751 003, Odisha, India.

'Department of Agricultural Structures, Civil and Environmental Engineering, College of Agricultural Engineering and Technology, Odisha University of Agriculture and Technology, Bhubaneswar751 003, Odisha, India.

Corresponding Author: Indrajeet Sahu, Department of Agricultural Processing and Food Engineering, College of Agricultural Engineering and Technology, Odisha University of Agriculture and Technology, Bhubaneswar-751 003, Odisha, India.

Email: indrajeetpfe@gmail.com

How to cite this article: Sahu, I., Rayaguru, K., Pattnaik, R.R. and Dash, S.K. (2021). Effect of Conditioning Methods on Mechanical Properties of Raw Bael Fruit. Asian Journal of Dairy and Food Research. DOI: 10.18805/ajdfr.DR-1788.

Submitted: 21-07-2021 Accepted: 11-10-2021 Online: 19-11-2021

value possessed by matured raw bael has been found to be much higher than that of ripe bael (Yadav et al., 2011, Bhardwaj and Nandal, 2015, Kaur and Kalia, 2017). More mature bael is more prone to spoilage due to a higher rate of catabolic process. As a result, for commercial scale processing of ripe bael, transportation, handling and processing within a restricted time frame is a key limitation. However, such problem can be reduced if mature raw bael is used for processing instead of the ripe ones. But the major 
obstacles for processing are its hard rind, numerous seeds along with gummy, mucilaginous materials and thus, it is difficult to be removed by hand at early maturity stage. New extraction technique is required to be followed for easy separation of fruit pulp from rind (Rayaguru et al. 2008). There is a need-to-know mechanical properties to develop an equipment that would be capable of slicing the raw bael fruits with minimal damage and loss. Therefore, the knowledge of mechanical properties of the commodity is required to design and improve the efficiency of processing equipment. Fruits and vegetables are exposed to different mechanical forces (shocks, vibrations, compressions) after harvest, resulting in tissue damage and a loss of quality. They are susceptible to bruises due to cell hardness and turgidity. Fruit firmness and resistance to splitting are strongly influenced by the mechanical behaviour of the skin or rind. Several studies have demonstrated that standard punctured test to examine the mechanical characteristics of fruit peel (apple, cucumber, grape berry, tomato) (Hussein et al. 2019). The influence of different temperature on fruit over a particular time interval shows variation in mechanical properties (Korkut and Hiziroglu, 2009). Effect of boiling in hot water on mechanical properties of aonla fruit showed that the surface hardness, pulp firmness and toughness reduced when the time of boiling in hot water was increased (Goyal et al., 2007). Sonawane et al. (2020) studied the effect of storage temperature on mechanical properties of mature bael fruit and he found that the orientation along the thickness needed less rupture force than orientation along the length and breadth. No research record was obtained on influence of different conditioning methods on mechanical properties of raw bael fruit for further processing without storage condition. Therefore, the current study was conducted to investigate selected mechanical properties (deformation, rupture force, firmness and toughness) of raw bael fruits and the influence of conditioning methods on these properties with the objective of forming a database for designing of slicing and cutting equipment.

\section{MATERIALS AND METHODS}

\section{Sample preparation}

Raw bael fruits of equal maturity (prior to ripening stage) of Narendra-1 variety were procured from the Odisha University of Agriculture and Technology (OUAT) campus, Bhubaneswar, Odisha in the year 2017-18. On the same day, the fruits were manually harvested and brought to the laboratory. The damaged fruits were removed and healthy fruits of uniform size (diameter and length) and appearance were allocated randomly into groups of ten for further testing. To study the effect of different pre-treatmentson the strength and textural parameters, the collected fruits (ten each) were subjected to different physical treatments like conditioning by normal water dipping $\left(25-27^{\circ} \mathrm{C}\right)$ for 24 hours, chilling (10$\left.11^{\circ} \mathrm{C}\right)$ for 24 hours, freezing $\left(4-5^{\circ} \mathrm{C}\right)$ for 12 hours and hot water dipping $\left(50-55^{\circ} \mathrm{C}\right)$ for 30 minutes. Average temperature and average relative humidity ranged between 22 to $25^{\circ} \mathrm{C}$ and 60 to $70 \%$. The sample kept under ambient condition for 24 hours was considered as control sample. The puncture test of the conditioned and controlled samples was carried out only after the treated fruits were equilibrated at room temperature. The energy requirement for heating, chilling and freezing is in the ratio of 10:27:37 and there is no energy require for normal water dipping treatment.

\section{Puncture test}

The puncture test was performed to assess the influence of various treatments on rupture force of the bael fruit under quasi-static loading. The tests were conducted using a $5 \mathrm{KN}$ Tinius Olsen Universal Testing Machine (UTM). A cylindrical indenter, $8 \mathrm{~mm}$ in dia, with a hemispherical tip was used. The indenter is moved at a consistent pace of $20 \mathrm{~mm} / \mathrm{min}$ by a computer-driven stepping motor. This instrument provides a displacement precision up to $1 \mathrm{~mm}$ and a force precision of $0.01 \mathrm{~N}$. On principle, puncture tests provide a pinpoint measure of firmness (Fig 1). In the experiment each fruit of all the groups belonging to different conditioning methods were subjected to the test. To reduce the influence of fruit heterogeneity on the data, individual measurements were taken at two locations (along polar and equatorial axis) of the same fruit and were averaged to describe the firmness.

\section{Firmness}

The average slope of the load displacement curve from zero to the point of rupture or failure was used to compute firmness $(\mathrm{N} / \mathrm{m})$. The slope of the curve was determined by dividing the puncture force $(F)$ by the displacement (D) caused by this force as:

$$
\text { Firmness }=F / D
$$

\section{Toughness}

The area under load displacement curves from zero to the point of rupture or failure was used to calculate toughness (rigidity), or mechanical energy or effort required for rupture. So, toughness was determined as:

$$
\text { Toughness }=1 / 2 \times F \times D
$$

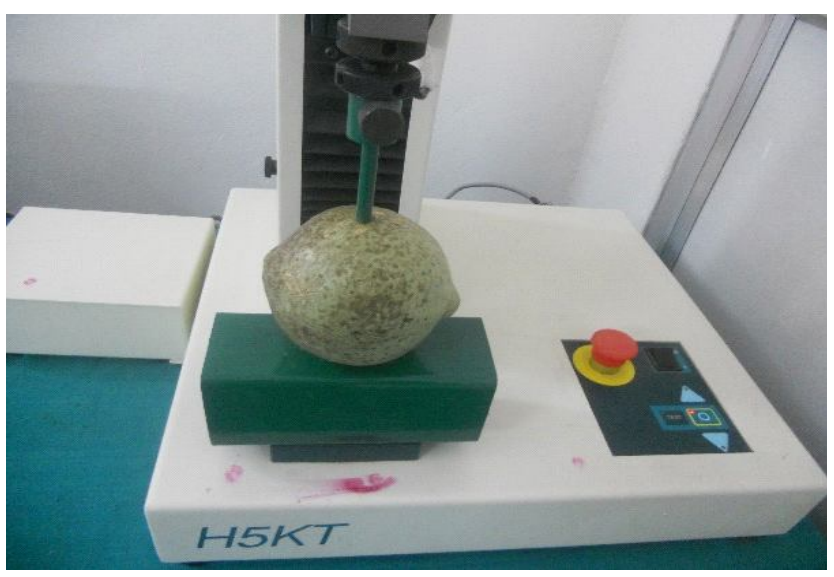

Fig 1: Puncture test of raw bael fruit. 
Effect of Conditioning Methods on Mechanical Properties of Raw Bael Fruit

\section{Statistical analysis}

All samples were prepared and subjected to test as described in the previous sections. Statistical analysis of the observations was carried out using MS Excel. The testing was undertaken for three replications from each treatment. The mean values of the observations along with the standard error of means were reported. Analysis of variance was carried out to determine the significance of difference $(p<0.05)$ between the treatment means with the help of least significant difference (LSD).

\section{RESULTS AND DISCUSSION \\ Effect of conditioning methods on mechanical Properties of bael}

Distinct peaks were observed on the force-displacement curves, which are related to the rupture force and firmness of the fruits. Typical curves obtained from puncture tests on a single fruit (two location) by hemispherical end probe are shown in Fig 2. The initial parts of the curves were nearly linearup to the rupture point (peak point) for all the samples irrespective of conditioning methods, however, the slopes were different. A more linearity and steeper slope could be seen for control sample (under ambient condition). Rupture force for control sample was $344.4 \pm 27.13 \mathrm{~N}$, whereas, it was found to be less in all the conditioned samples (Table1). The minimum rupture force of $192.6 \pm 14.41 \mathrm{~N}$ was observed for the samples conditioned with freezing. No significant $(P>0.05)$ difference between the rupture force for the normal water dipped sample (about $276.2 \pm 24.04 \mathrm{~N}$ ) and chilled samples $(282 \pm 12.44 \mathrm{~N})$ could be observed. Hot water dipping reduced the rupture force to a greater extent $(215.3 \pm 29.27 \mathrm{~N})$ than the other methods. No remarkable variation in the deformation could be observed among the samples, which ranged between $5.79 \pm 0.13$ to $7.62 \pm 0.87 \mathrm{~mm}$ for different samples.

\section{Firmness}

There was a significant variation $(P<0.05)$ in firmness of the samples with different conditioning methods as observed in Table 1. The firmness of control sample $(47.60 \pm 5.84 \mathrm{~N} / \mathrm{mm})$ and that of normal water dipped samples $(47.62 \pm 3.03 \mathrm{~N} /$ $\mathrm{mm}$ ) were very close to each other with no significant difference. Maximum rupture force requirement of control sample was associated with relatively higher deformation $(7.23 \pm 0.77 \mathrm{~mm})$, where as normal water dipped samples had lowest deformation $(5.79 \pm 0.13 \mathrm{~mm})$ for which both the sample had almost equal firmness (47.6 N/mm) (Fig 4). Fig
3 showed that the lowest firmness (i.e. $25.25 \mathrm{~N} / \mathrm{mm}$ ) was achieved by the bael fruit conditioned by freezing followedby hot water dipped and chilled sample. This indicated that therind firmness could be reduced by proper conditioning prior to processing. The highest reduction of firmness was observed by the conditioning method of freezing at a temperature $\left(4-5^{\circ} \mathrm{C}\right)$.

\section{Toughness}

Fig 5 indicates the highest toughness of $1245.86 \pm 139.4$ $\mathrm{Nmm}$ in control sample. Significant decrease, about 20 to $30 \%$ in the toughness was found in all the conditioned samples (Table 1). Differences in the toughness was observed to be dependent on conditioning methods. This decrease might have been resulted from withering of the rind and/or the underlying pericarp tissue leading to reduction in work required to rupture the rind. However, this

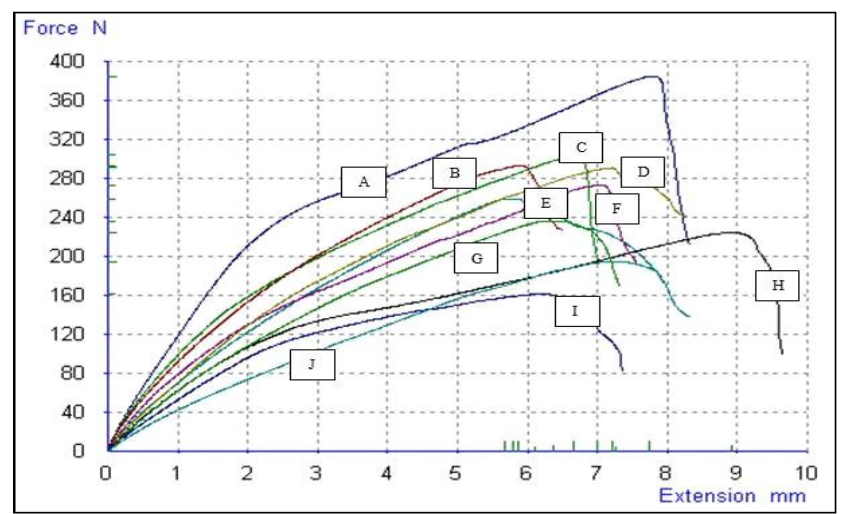

Fig 2: Force-Deformation curve for puncture test for control and conditioned samples.

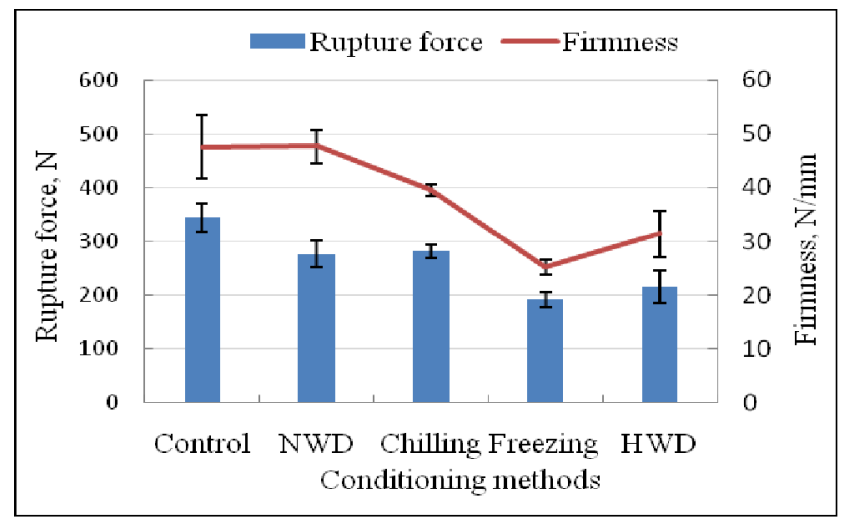

Fig 3: Effect of treatments on rupture force and firmness of bael.

Table 1: Effect of conditioning on firmness and toughness values with respect to different treatments on fruits from force-deformation data.

\begin{tabular}{lcccc}
\hline Conditioning methods & Rupture force $(\mathrm{N})$ & Deformation $(\mathrm{mm})$ & Firmness $(\mathrm{N} / \mathrm{mm})$ & Toughness $(\mathrm{Nmm})$ \\
\hline Control & $344.4 \pm 27.13$ & $7.23 \pm 0.77$ & $47.60 \pm 5.84$ & $1245.86 \pm 139.4$ \\
Normal water dipping (NWD) & $276.2 \pm 24.04$ & $5.79 \pm 0.13$ & $47.62 \pm 3.03$ & $800.91 \pm 88.36$ \\
Chilling & $282.0 \pm 12.44$ & $7.12 \pm 0.12$ & $39.57 \pm 1.07$ & $1004.63 \pm 61.28$ \\
Freezing & $192.6 \pm 14.41$ & $7.62 \pm 0.87$ & $25.25 \pm 1.39$ & $734.28 \pm 149.74$ \\
Hot water dipping (HWD) & $215.3 \pm 29.27$ & $6.85 \pm 0.63$ & $31.41 \pm 4.21$ & $737.67 \pm 82.17$ \\
\hline
\end{tabular}




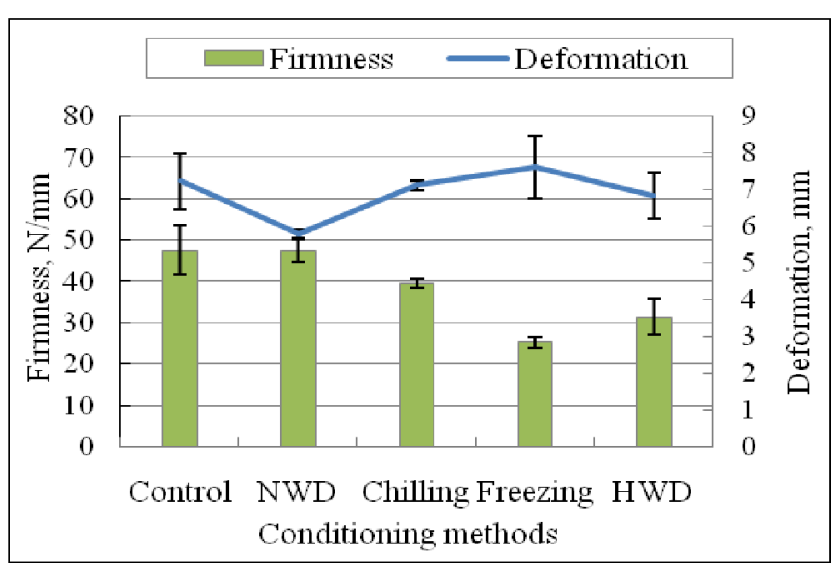

Fig 4: Effect of treatments on deformation and firmness of bael.

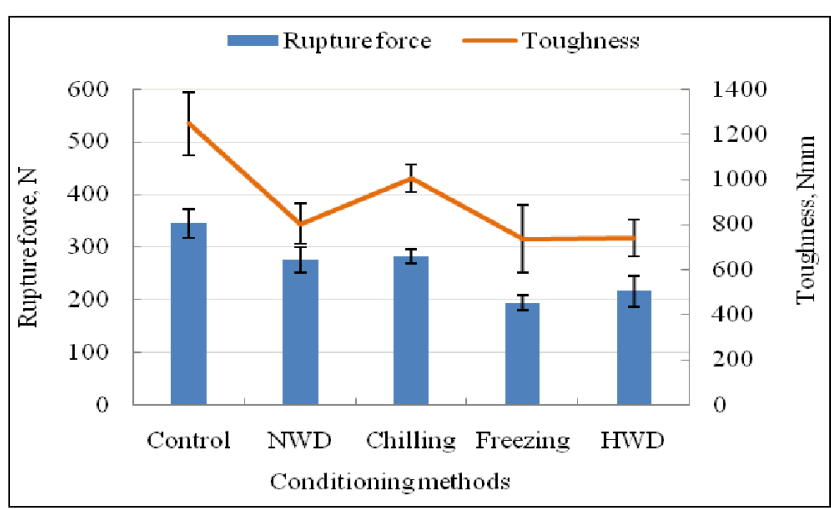

Fig 5: Effect of treatments on rupture force and toughness of bael.

percentage remained almost same for hot water dipped and frozen samples with minimum toughness values. Normal water dipped and chilled samples had toughness values of $800.91 \pm 88.36 \mathrm{Nmm}$ and $1004.63 \pm 61.28 \mathrm{Nmm}$ respectively. Though no significant difference in toughness was observed between the frozen and hot water dipped samples, the firmness of frozen sample was significantly lower than that of hot water dipped sample. Further the colour of hot water dipped sample changed to deep brown whereas that of frozen sample remained fresh with greenish-yellow colour. This will lead to higher consumer appeal.

\section{CONCLUSION}

This study concludes that the conditioning methods significantly affected the mechanical properties of raw bael fruit. Freezing $\left(4-5^{\circ} \mathrm{C}\right)$ for 12 hours was found to be most suitable conditioning method followed by chilling and normal water dipping. But the method of hot water dipping is not recommended as it changed the color of the fruit adversely. Therefore, mechanical properties of fruits influence their behaviour throughout preparation, storage, distribution and consumption of product. The effect of different conditioning methods on mechanical properties and their dependency on temperature is necessary for selecting appropriate equipment for transportation, mixing and size reduction, as well as assessing mechanical stress tolerance during postharvest operation.

\section{ACKNOWLEDGEMENT}

The author is grateful to CAET, OUAT, Bhubaneswar for providing necessary laboratory and research facilities during the process. The corresponding author expresses deep gratitude to OUAT for providing merit fellowship during his PhD program.

\section{REFERENCES}

Annual Statistical Report of NHB (2015-2016). Indian Production of Bael.

Baliga, M.S., Bhat, H.P., Joseph, N. and Fazal, F. (2011). Phytochemistry and medicinal uses of the bael fruit (Aegle marmelos Correa): A concise review. Food Research International. 44: 1768-1775.

Bhardwaj, R.L. and Nandal, U. (2015). Nutritional and therapeutic potential of bael (Aegle marmelos Corr.) fruit juice: A review. Nutrition and Food Science. 45(6): 895-919.

Goyal, R.K., Kingsly, A.R.P., Kumar P. and Walia H. (2007). Physical and mechanical properties of aonla fruits. Journal of food Engineering. 82: 595-599.

Hussein, Z., Fawole, O.A. and Opara, U.L. (2019). Harvest and Postharvest Factors Affecting Bruise Damage of Fresh Fruits. Horticultural Plant Journal. 167(5): 1-28.

Kaur, A. and Kalia, M. (2017). Physico chemical analysis of bael (Aegle Marmelos) fruit pulp, seed and pericarp. Chemical Science Review and Letters. 6(22): 1213-1218.

Korkut, S. and Hiziroglu, S. (2009). Effect of heat treatment on mechanical properties of hazelnut wood (Corylus colurna L.). Materials and Design. 30(5): 1853-1858.

Lakht-e-Zehra, Asadullah, Dar, N.G., Saleem, N., Soomro, U.A., Afzal, W., Naqvi, B. and Jamil, K. (2015). Nutritional exploration of leaves, seed and fruit of bael (Aegle marmelos L.) grown in Karachi region. Pakistan Journal of Biochemistry and Molecular Biology. 48(3): 61-65.

Rayaguru, K., Sahoo, N.R. and Khan, Md. K. (2008). Effect of storage on quality of raw stone apple ready-to-serve beverage. Journal of Agricultural Engineering. 45(1): 62-67.

Singh, A., Sharma, H.K., Kaushal, P. and Upadhyay, A. (2014). Bael (Aegle marmelos Correa) products processing: A review. African Journal of Food Science. 8(5): 204-215.

Sonawane, A., Pathak, S.S. and Pradhan, R.C. (2020). Physical, thermal and mechanical properties of bael fruit. Journal of Food Process Engineering. 43(6): 1-9.

Yadav, N., Singh, P. and Mehrotra, R. (2011). Determination of some ethnomedicinally important constituents of Aegle marmelos fruit during different stages of ripening. Chinese Journal of Natural Medicines. 9(2): 204-209. 